\title{
Adenomyoma of the main biliary tract mimicking cholongiocarcinoma
}

\author{
Sara Morabit*, Fatiha Bouhamou, Sanaa Berrag and Mouna Tazaourte \\ Department of Gastroenterology, Military Hospital Mohamed V, Rabat, Morocco
}

\begin{abstract}
Adenomyoma occurs most commonly in the fundus of the gallbladder, seldom in other parts of the gallbladder and rarely in the extrahepatic biliary tree. Adenomyoma of the biliary tract is a benign neoplasm but its clinical, radiological and intraoperative features can mimick cholongiocarcinoma. These similarities may yield to useless pancreatoduodenectomy. We report a case of a 70-year-old patient who underwent a cephalic duodenopancreatectomy due to clinical and radiological evidence of underlying malignant neoplasm. The histopathology results revealed an adenomyoma of the main biliary tract.
\end{abstract}

\section{Introduction}

Benign tumours of the biliary tract are exceedingly rare pathological findings but are of clinical importance because of the differential diagnosis of the more common carcinoma of the bile ducts. Growing locally, they may be classified in one of the following histopathological entities: (1) polyps, adenomas, adenomatous papillomas, and multiple biliary papillomatosis ; (2) adenomyosis; (3) granular cell myoblastomas; (4) neural tumours; (5) leiomyomas, and (6) various other entities such as pseudotumors, inflammatory masses, and heterotopic tissue. The most common benign bile duct tumours are those arising from the glandular epithelium lining the ducts.

The objective of this work was, based on the observation of our patient and on the review of the literature, to study the characteristics, morphological and histological studies of adenomyoma of the main biliary tract in order to focus on this differential diagnosis of pancreaticobiliary tumors and try to avoid morbid and unnecessary therapeutic gestures.

\section{Case report}

A 70-year-old woman was admitted to our gastroenterology unit to investigate a 2-months history of severe pain right hypochondrial as well as epigastric. She had never experienced jaundice or fever, and she did not present with weight loss. Her medical history included viral hepatitis $\mathrm{c}$ cured 10 years ago, having also a surgical hysterectomy at the age of 50 years. The physical examination results were unremarkable. Blood tests showed normal hepatic measurements: aspartate transaminase $30 \mathrm{U} / \mathrm{L}$, alanine transaminase $22 \mathrm{U} / \mathrm{L}$, alkaline phosphatase $32 \mathrm{U} / \mathrm{L}, \gamma$-glutamyl transferase $81 \mathrm{U} / \mathrm{L}$, total bilirubin 13 $\mathrm{mg} / \mathrm{dL}$, and conjugated bilirubin $07 \mathrm{mg} / \mathrm{dL}$. The tumour markers CEA and CA-19.9, as well as immunoglobulinG4 antibodies, were within normal limits. Ultrasonography showed dilation of the main bile duct to $12 \mathrm{~mm}$ without visible obstacle. Computed tomography and the MRIbiliary showed a dilation of the main bile duct with an endoluminal material of the lower bile duct suspecting cholongiocarcinoma (Figure 1).

An endoscopic retrograde cholangiopancreatography, decided to remove a lithiasic obstacle, showed an indurated papilla, reshaped and

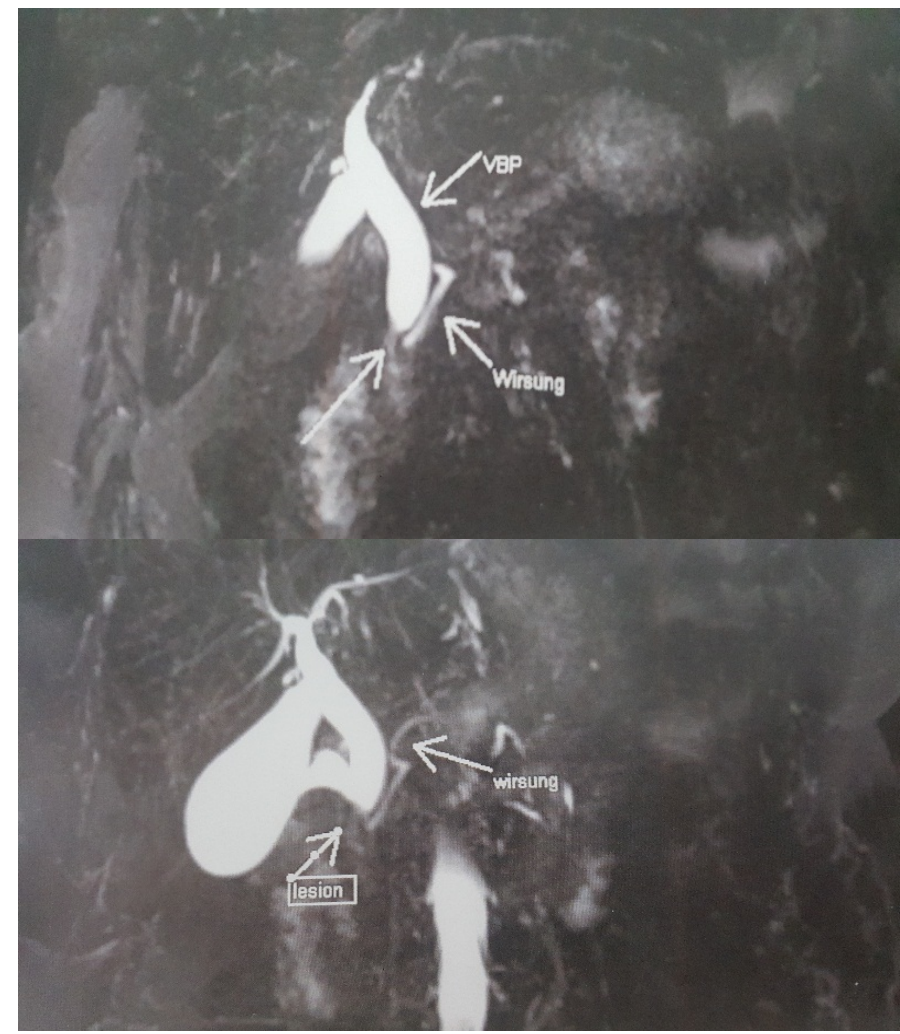

Figures 1. Biliary MRI showing a lesional process in the main bile duct

${ }^{*}$ Correspondence to: Sara Morabit, Department of Gastroenterology, Military Hospital Mohamed V, Rabat, Morocco, Tel: 00212633323970; E-mail: dr.saramor@gmail.com

key words: adenomyoma, main biliary tract, cephalic duodenopancreatectomy, cholongiocarcinoma

Received: January 06, 2020; Accepted: January 20, 2020; Published: January 24, 2020 
enlarged, evoking a tumor. Despite several attempts, it could not be catheterized. The biopsy, superficial, was not contributory.

Given the macroscopic aspect and the clinical context, the surgical intervention was decided. Cephalicduodenopancreatectomy with pancreaticogastric anastomosis was performed. The operating suites were simple.

Histological examination showed the presence of an adenomyoma of the main bile duct, $1.8 \mathrm{~cm}$ in diameter, without signs of malignancy.

\section{Discussion}

Adenomyoma is a rare benign disease, described on the entirety of the biliary tree, especially at the gallbladder where it is most frequently encountered. This anatomopathological entity has been badly individualized in the past, often confused with adenoma [1,2] and stenosing papillitis [3]. It's Bravet, in 1913, who first described this neotraining, in particular located at the level of the papilla [4]. To date, 59 cases of bile duct adenomyoma have been reported. Adding our case, 60 cases of adenomyoma can be studied: most (45/61) were symptomatic (73.8\%), few (9.8\%) were reported asymptomatic. Localization at the main biliary tract level appears rare, but of great clinical consequence since the differential diagnoses are the cholangiocarcinoma and malignant tumors of the biliopancreatic crossroads. Burhans and Myers [5] estimated the incidence of adenomyoma to be $0.1 \%$ of all procedures on the biliary tree. On the extrahepatic bile ducts, it would constitute $0.6 \%$ of all neoformations. However, several autopsy studies have shown an incidence of Vater's bulb adenomyoma close to 50\% [6] (with lesions 2 to $5 \mathrm{~mm}$ in diameter) or even higher (54\% and 70\%) [2,7-10]. The review of the cases described shows that adenomyoma is diagnosed in adult patients (average age: 59 years, median age: 63 years) of both sexes (data known for 46 cases including 26 women and 20 men). The clinical manifestations are due to the obstruction of bile ducts and therefore not very specific. The reasons for the passage to this symptomatic form are unexplained. Jaundice was the most frequent sign, observed in 30 cases (66.7\%): 14 cases in the form of naked jaundice (31.1\%) while in 16 cases their associated pain (35.5\%). Pain syndrome, as the sole symptom, was observed in 9 cases (20\%), while cholangitis was reported in 6 cases (13.3\%). The non-specific clinic signs, such as asthenia, dyspepsia and weight loss, are reported in 13 cases $(28.8 \%)$. The clinical presentation of a main biliary tract adenomyoma is therefore not very specific and close to that of neoplastic obstacles, as in our observations. The imagery does not allow to differentiate in budding forms with adenoma and in stenosing forms with cholangiocarcinoma or cancers of the head of the pancreas. Only biopsies are conclusive.

In general, adenomyoma of the main biliary tract is a benign pathology of the ampullary region but also of the whole biliary tree.
These are small lesions that appear either stenotic or burgeoning, often mistaken for cancer and treated in the majority of cases by cephalic duodenopancreatectomy excessive a priori. Knowledge of this pathology therefore grows to encourage an endoscopic exploration of ampullary obstacles, especially in the absence of dilation of the Wirsung. In fact, a deep biopsy can allow to reach this diagnosis of benignity and to propose a conservative treatment. In case of intra- or extrahepatic supra-papillary, common bile duct doubt with a tumor lesion most often persist and it seems difficult to avoid a more or less extensive excision.

\section{Conclusion}

Adenomyoma of the main bile duct is an extremely rare benign pathology, its incidence is estimated at $0.1 \%$ of all operations on the biliary tree. It simulates clinically and radiologically a malignant tumour pathology, these similarities most often lead to the realization of a cephalic duodenopancreatectomy, a morbid and excessive gesture, is important in order to push the invasive explorations in front of an obstacle of the bile duct presenting as neoplastic. This attitude could avoid certain duodenopancreatectomies illegitimate cephalic.

\section{References}

1. Thomas P, Delpero JR, Monges G, Houvenaeghel G, Capobianco C, et al. (1990) Adenomyoma of the distal common bile duct. An uncommon cause of stenosis of the extrahepatic bile duct. Gastroenterol Clin Biol 14: 283-285. [Crossref]

2. Kayahara M, Ohta T, Kitagawa H, Miwa K, Urabe T, et al. (2001) Adenomyomatosis of the papilla of Vater: a case illustrating diagnostic difficulties. Dig Surg 18: 139-142. [Crossref]

3. Dowdy GS Jr, Olin WG Jr, Shelton EL Jr, Waldron GW (1962) Benign tumour of the extrahepatics bile ducts. Report of three cases and review of the literature. Arch Surg 85: 165-175. [Crossref]

4. Moore SW, McElwee RS, Romiti C (1952) Benign tumours of the biliary tract. $J \mathrm{Am}$ Med Assoc 150: 999-1003. [Crossref]

5. Hammarstrom LE, Holmin T, Stenram U (1997) Adenomyoma of the ampulla of Vater: an uncommon cause of bile duct obstruction. Surg Laparosc Endosc 7: 388393. [Crossref]

6. Bravet G (1913) Benign tumors of the extrahepatic bile ducts. Thesis. Lyon. [Crossref]

7. Myers BR (1971) Benign neoplasms of the extrahepatic biliary ducts. Am Surg 37: 161-166.

8. Baggenstoss AH (1938) Major duodenal papilla: variations of pathologic interest and lesions of mucosa. Arch Pathol 26: 853-868.

9. Flejou JF, Molas G (1989) Adenomyoma of the papilla, an exceptional tumor of pancreatic origin (res). Gastroenterol Clin Biol 13: 300

10. Aoun N, Zafatayeff S, Smayra T, Haddad-Zebouni S, Tohme C, et al. (2005) Adenomyoma of the ampullary region: imaging findings in four patients. Abdom Imaging 30: 86-89. [Crossref]

Copyright: (C2020 Morabit S. This is an open-access article distributed under the terms of the Creative Commons Attribution License, which permits unrestricted use, distribution, and reproduction in any medium, provided the original author and source are credited. 